\title{
Test of levelling techniques for old aerogeophysical database
}

\section{Tomás Dalpiaz Strieder (Engenharia Geológica, CEng - UFPel, Pelotas - RS)}

Adelir José Strieder (Engenharia Geológica, CEng - UFPel, Pelotas - RS)

Telmo F. P. de Quadros (ANM, Porto Alegre - RS)

\section{Copyright 2019, SBGf - Sociedade Brasileira de Geofísica}

This paper was prepared for presentation during the $16^{\text {th }}$ International Congress of the Brazilian Geophysical Society held in Rio de Janeiro, Brazil, 19-22 August 2019.

Contents of this paper were reviewed by the Technical Committee of the $16^{\text {th }}$ International Congress of the Brazilian Geophysical Society and do not necessarily represent any position of the SBGf, its officers or members. Electronic reproduction or storage of any part of this paper for commercial purposes without the written consent of the Brazilian Geophysical Society is prohibited.

\section{Abstract}

This paper presents the results of a line-to-line levelling technique applied onto the 1010 Camaquã Aerogeophysical Project (DNPM/CPRM, 1973). The lineto-line levelling technique is specially designed to aerogeophysical surveys which do not have tie-lines, as is the case for 1010 Project. This levelling technique was applied onto the original database of the 1010 Project and enabled levelling and grouping together their both $E$ and W parts. The line-to-line levelling technique was effective in removing flight lines artifacts, and in maximizing geological signal that had been removed in previous levelling processes.

\section{Introduction}

The levelling techniques are applied to maximize the geological features signals, and to reduce or completely remove environmental noise introduced during geophysical surveys. Traditional levelling processes include polynomial adjusts and filtering, but they should be carefully applied since they can remove genuine geological information from geophysical database.

Old aerogeophysical surveys were carried out under lower technological support than nowadays. Horizontal (navigational effects) and vertical (altitude variation) positioning are one of important source of mismatch between flight lines and stripping after aerogeophysical signal processing (Luyendyk, 1997).

The Brazilian 1970' decade aerogeophysical surveys were carried out by DNPM (currently Agência Nacional de Mineração, ANM) and CPRM (Geological Survey of Brazil) Agreement. They are included in 1000 Project Series (http://www.cprm.gov.br/aero/1000/aero1000.htm).

These databases were later transformed into digital format by Paterson, Grant \& Watson Limited (PGW) through different projects supported mainly by CPRM. Some of the gamma-spectrometry databases were converted from original cps to element concentration (\% eTh, eU, mR/h) by means of Brazil Airborne Radiometric Mapping Project (BARMP).
Even though some degree of levelling was performed onto the aerogeophysical database by PGW Ltd., significant stripping can still be detected in gridded maps (e.g. Figure 1). A comparison of original and levelled data (before the transformation to element concentration) for each flight line reveals that levelling was just a kind of low pass filter (e.g. Figure 2). Indeed, levelling between adjacent flight lines was poorly effective.

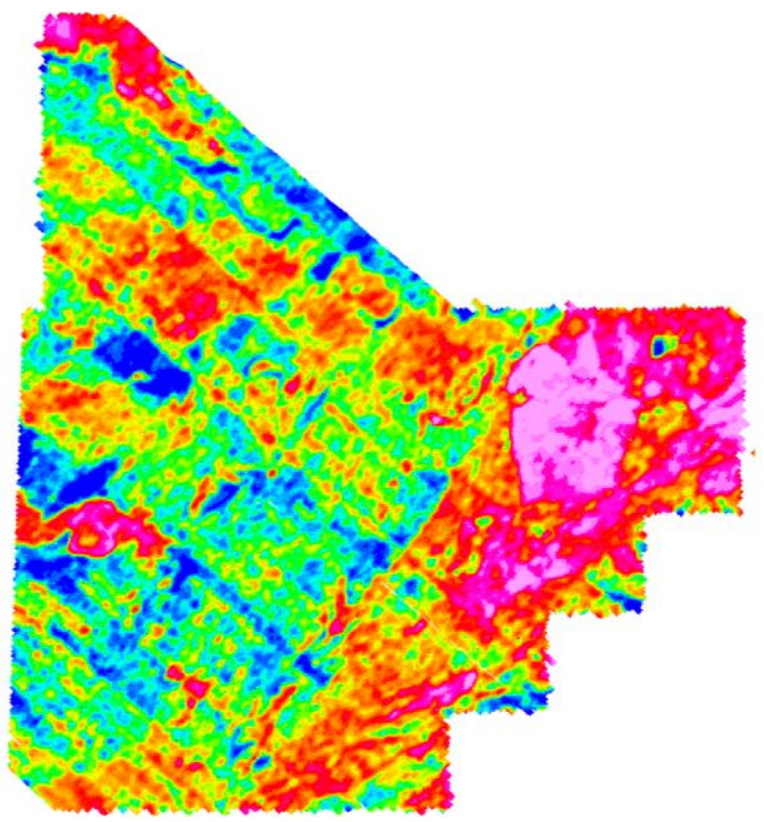

Figure 1 - Levelled K (cp2s) grid to $\mathrm{E}$ part of the Camaquã Aerogeophysical Project (1010, RS, 1973). Gridding was performed through simple Kriging (N35E). To note the NW flight line stripping.

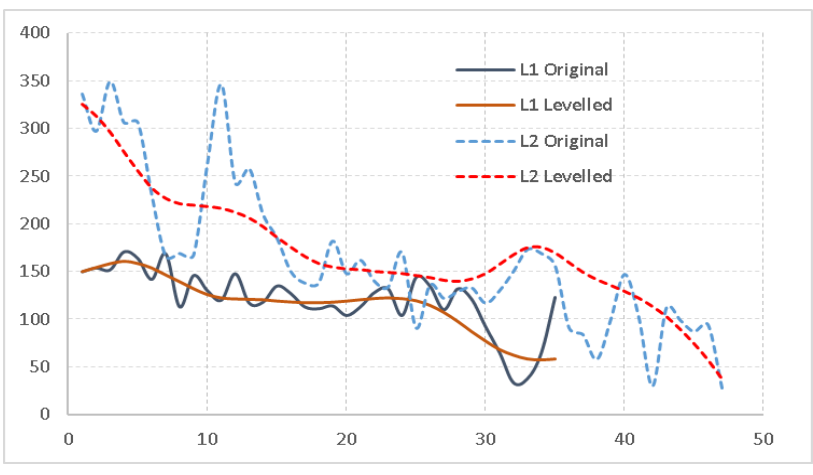

Figure $2-\mathrm{K}$ intensity (cp2s) for two adjacent flight lines of the Camaquã Aerogeophysical Project (1010, RS, 1973). 
The aim of this paper is to present the results for different levelling techniques onto the aerogeophysical database of the Brazilian 1970's decade surveys.

The main purpose in dealing with different levelling techniques is to select ones that show poor or none low pass filter effect. This procedure intends to evaluate signal/noise relationship and gridded maps quality for geologic-structural interpretation.

The aerogeophysical database used for levelling techniques tests was Camaquã Project (1010), which covers western part of the Sul-riograndense Shield. It was flown from 16/06/1972 to 07/05/1973. The database is divided in two parts ( $E$ and $W$ ), due to UTM zone limit at Longitude $54^{\circ} \mathrm{W}$. The element concentration data is available only for the $E$ part. And, no records of date each survey lines were flown is available, in order to better constraint Earth Magnetic Field and IGRF.

The database processing and design of levelling techniques algorithms were all performed in SCILAB® software. "SCILAB is a free and open source software for engineers and scientists" (https://www.scilab.org/). Visualization and refinements were done in GEOSOFT®.

\section{Levelling Procedures and Methods}

According to Urquhart (1988), Minty (1991) and Reeves (1993), levelling operations are executed in three distinct steps:

i) Base station subtraction to remove diurnal variation in field stations. In the case of magnetic surveys, it removes diurnal variation of Earth magnetic field;

ii) Levelling at line intersections. According to Reeves (1993), this levelling is a method to eliminate environmental variations using pairs of values at intersections between the flight and tie lines. This leveling is performed through polynomial function that adjust the flight lines to the control lines.

iii) Micro-levelling. The levelling process can input lowamplitude noise along the flight lines data, what is known as "corrugations". In order to correct that, the microleveling, or "decorrugation", process is applied on the data. Micro-leveling is "a filtering process that seeks to identify and remove features whose wavelengths in the across-line direction are equal to twice the line spacing and in the along line direction are equal to the spacing between tie-lines" (Reeves, 1993).

The Camaquã Project database 1010 does not have tielines available for traditional leveling process. To remedy that, Huang (2008) presented an alternative method to level the data line-to-line.

Huang's (2008) method uses to choose a reference line $\left(d^{0}\right)$, preferably one with little or free of leveling errors. It is possible to pre-process this line in order to minimize error, since any faulty data will be transmitted to adjacent lines and, consequently, to the rest of the database.
Two adjacent lines $\left(\mathrm{d}^{1}\right.$ and $\left.\mathrm{d}^{0}\right)$, however, do not fit (Figure $3 A)$, due to leveling errors. These errors can be expressed as a function of distance $f(\mathrm{x})$, as shown in figure 3B. The difference between the $d^{1}$ line and its errors will, therefore, result in the leveled data:

$$
\mathrm{d}^{1 \mathrm{~L}}=\mathrm{d}^{1}-f(\mathrm{x})
$$

Assuming the data is continuous and correlated line-toline, the difference between $\mathrm{d}^{0}$ and $\mathrm{d}^{1 \mathrm{~L}}$ should be minimal:

$$
\left\|\left(\mathrm{d}^{1}-\mathrm{d}^{0}\right)-f(\mathrm{x})\right\|^{2}=\min
$$

One must, then, choose the model that best defines the leveling error $f(\mathrm{x})$. After the adjacent line $\mathrm{d}^{1}$ is corrected based on the chosen model, it then serves as reference in leveling the next line.
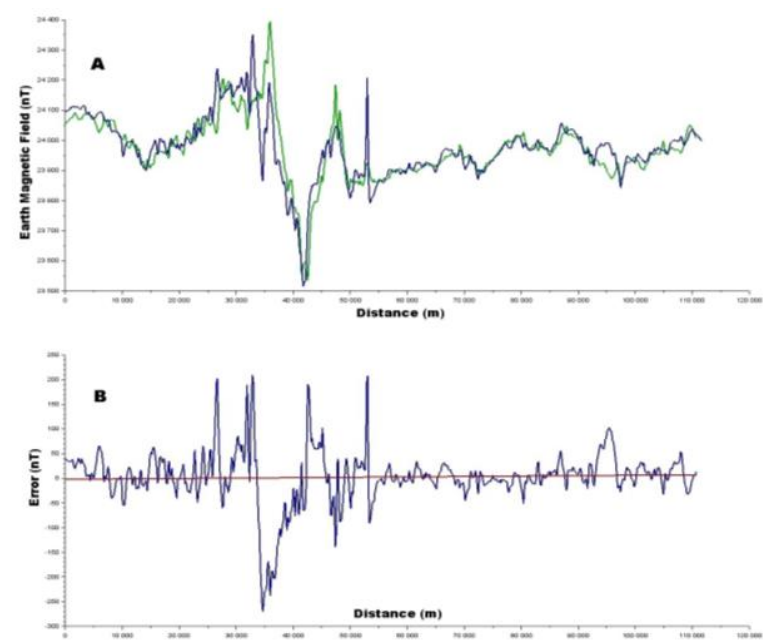

Figure 3 - Adjacent flight lines (A) of the 1010 Camaquã Project showing levelling discrepancies, and the misfit error (B) between them as a function of distance. The green line is $d^{0}$, and blue line is $d^{1}$ in figure $A$.

First and second degrees polynomial models were applied to the 1010 Camaquã Project flight lines. However, since the flight lines discrepancies are too high (see Figure 1), an iterative process was tried to get a better adjustment between flight lines.

\section{Results and discussions}

Most the levelling procedures have been presented to aeromagnetometric (Urquhart, 1988; Minty, 1991; Reeves, 1993) and to EM (Huang, 2008) data surveys. However, as pointed out by Reeves (1993), the methods can also be applied to gammaspectrometric data.

This paper focus on levelling gammaspectrometric data of the 1010 Camaquã Project. The quality analysis of the levelling procedure upon original counts of the gammaspectrometric data $(\mathrm{K}, \mathrm{Th}$, and $\mathrm{U})$ is presented in figures 4,5 and 6 . They show the histograms of original and newly levelled gamma-counts, and their descriptive statistical summary. 
Figure 4 shows that histograms for both, original $(A)$ and levelled (B) $\mathrm{K}$ counts are positively asymmetric and leptokurtic. The means for levelled $\mathrm{K}$ counts are $\sim 50$ counts higher than the original ones; this shows that levelled $\mathrm{K}$ counts somewhat displaced toward higher values. However, the main parameters describing data distribution (standard deviation, variance, skewness, kurtosis and interquartile range) do not present significant differences between them.
The same results can be observed in Th and $U$ (cp2s) histograms and their descriptive statistics (Figures 5 and $6)$. They show that levelling procedure do not changed data (Th and $U$ ) distribution, even the means are a little bit higher than the original ones. For both (Th and $U$ ), the standard deviation, variance, skewness, kurtosis and interquartile range are not significantly different if considered the original and levelled values.
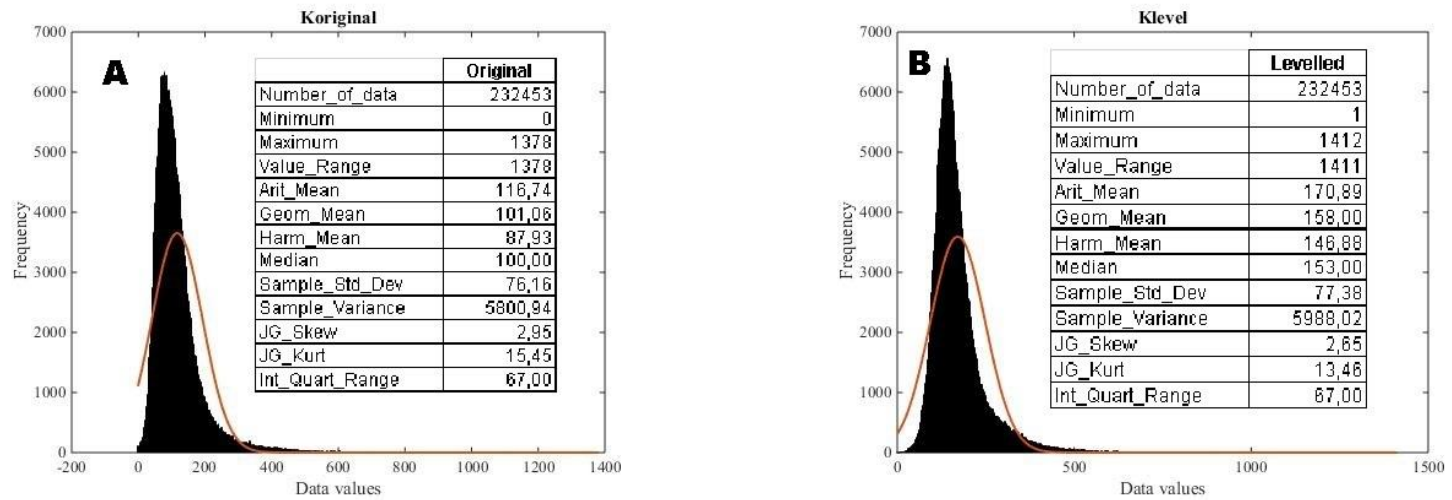

Figure 4 - Histograms for original (A) and levelled (B) K counts (cp2s) of the Camaquã Project 1010), and their statistical analysis. Red curve is the CDF for data distribution in the histogram.
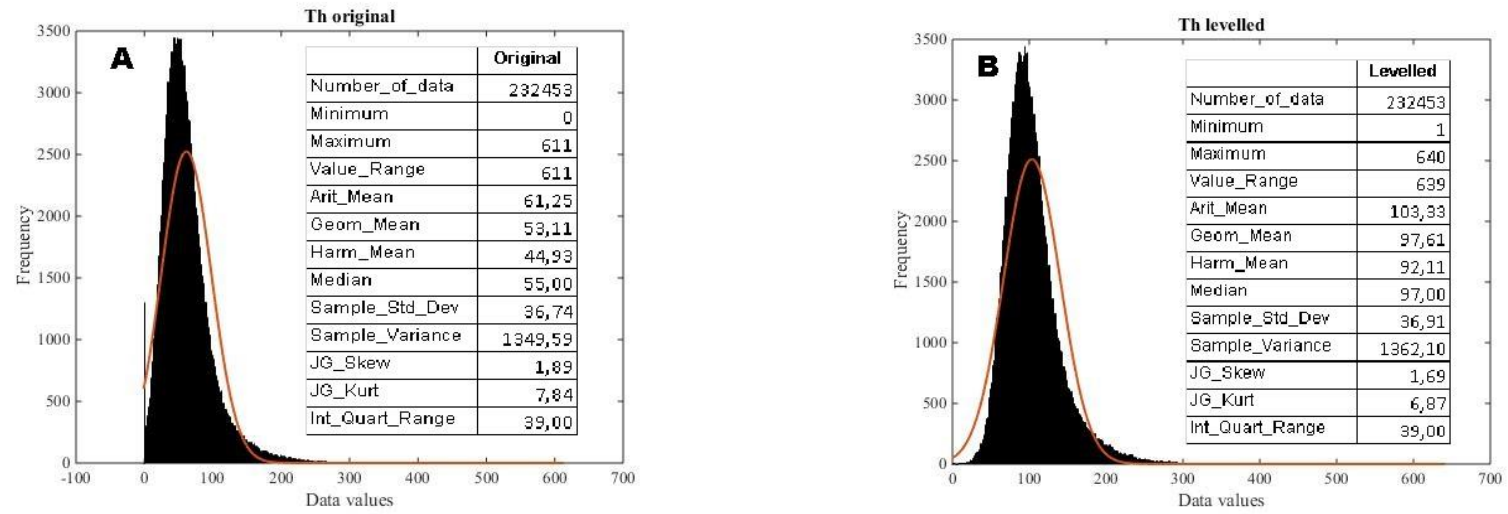

Figure 5 - Histograms for original (A) and levelled (B) Th counts (cp2s) of the Camaquã Project 1010, and their statistical analysis. Red curve is the CDF for data distribution in the histogram.
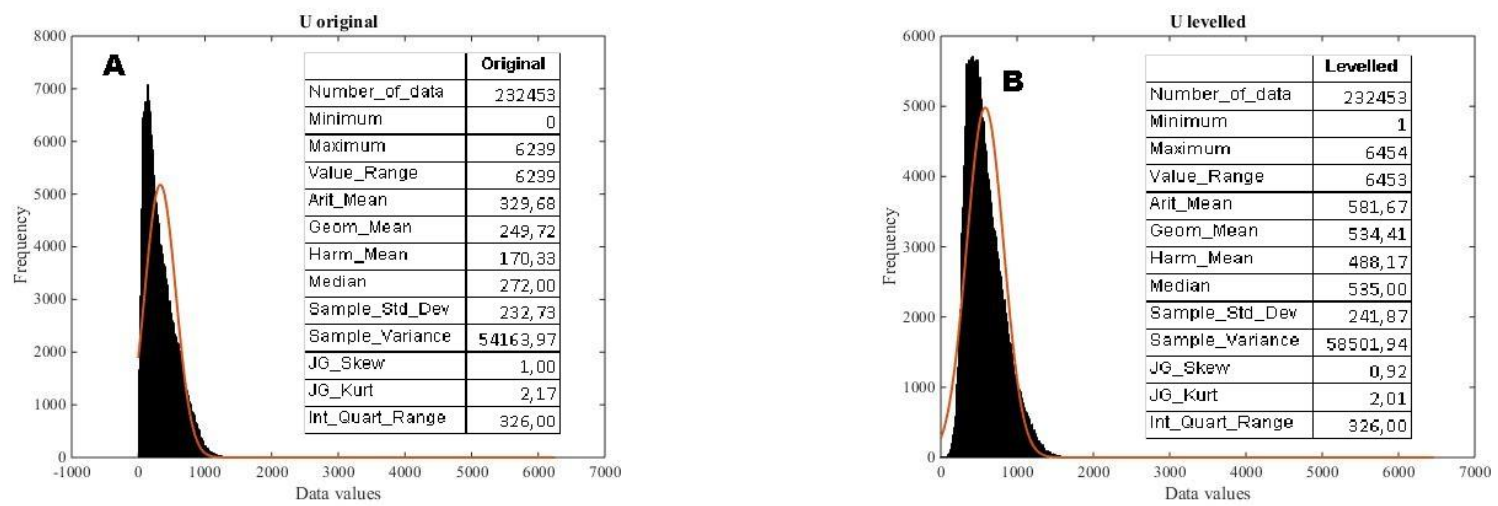

Figure 6 - Histograms for original (A) and levelled (B) U counts (cp2s) of the Camaquã Project 1010), and their statistical analysis. Red curve is the CDF for data distribution in the histogram. 
The applied method was also able to level and adjust $E$ and $W$ databases of the 1010 Camaquã Project, as can be seen in figure 7 . Then, histograms of figures 4,5 and 6 compute the complete database for 1010 Camaquã Project.

Figure 7 shows the grids for $\mathrm{K}$, Th and $\mathrm{U}$ gamma counts (respectively, A, B and C). Its to note the absence of NW flight line stripping, mainly if one compares figures 1 and 7 ( $\mathrm{K}$ counts grid) for original and levelled data, respectively.

It can be observed in figures $7 \mathrm{~A}, 7 \mathrm{~B}$ and $7 \mathrm{C}$ that the main geological features of the western part of the Sulriograndense Shield are laterally followed and are better defined than before.

The results described above account for the main assumption of the Huang's (2008) method: "the geophysical field is continuous from line to line". However, it does not propagate error laterally were the source signal disappear along geological structure. In other words, it does not create geophysical artifacts. This kind of features can be observed mainly for NE oriented geological structures of the western part of the Sulriograndense Shield.

These results are best observed when one generates a ternary map with $\mathrm{K}, \mathrm{Th}$, and $\mathrm{U}$ levelled counts (Figure 8). The ternary grid map does reveal the geological and structural features of this part of the Sul-riograndense Shield, and does not show flight lines artifacts.

\section{Conclusions}

It was demonstrated that the levelling technique applied to the 1010 Camaquã Geophysical Project identified and removed most of the "features whose wavelengths in the across-line direction are equal to twice the line spacing and in the along line direction are equal to the spacing between tie-lines" as pointed out by Reeves (1993).

In fact, the applied levelling technique operated both, levelling and micro-levelling, at same time.

The results demonstrate that levelling technique removed low-wavelengths features and maximized the geological information present in the 1010 Camaquã Geophysical Project.

The danger of filtering process usually applied as levelling, or micro-levelling is to remove genuine geological information from geophysical database. And, in this aspect, the levelling technique here presented cannot be classified as a type of filtering process. But it is more correctly envisaged as an "error correction" levelling or adjustment based on the difference of aerogeophysical signal due to environmental conditions, assuming that sources are at the same conditions.
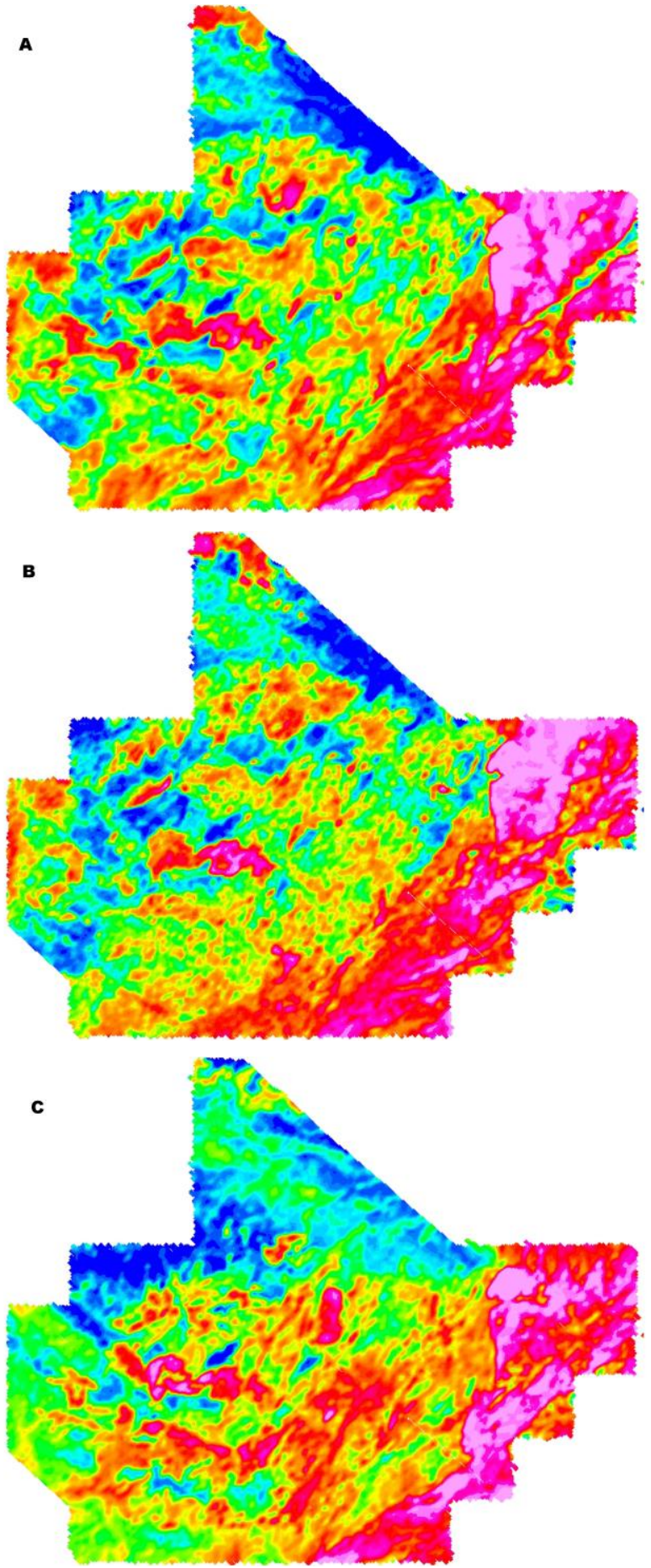

Figure 7 - Grid to levelled complete database (E and W parts) of the Camaquã Aerogeophysical Project (Project 1010, RS, 1973). A) K cp2s counts; B) Th cp2s counts; C) $U$ cp2s counts. Levelling technique according to Huang (2008). Gridding was performed through simple Kriging (N35E). 


\section{Acknowledgments}

The authors wish to thank CPRM (Serviço Geológico do Brasiil), specially Geol. José Luis Andriotti, and Geof. Luiz G R Pinto, which promptly made available the geophysical database of the Sul-riograndense Shield projects for this research group. The authors wish also to thank ANM (Agência Nacional de Mineração) for supporting the fieldworks in this project.

\section{References}

LUYENDYK APJ. 1997. Processing of airborne magnetic data. AGSO Journal of Australian Geology \& Geophysics, 17(2), 31-38.
HUANG H. 2008. Airborne geophysical data leveling based on line-to-line correlations. GEOPHYSICS, 73(3), F83-F89.

MINTY BRS. 1991. Simple Micro-Levelling for Aeromagnetic Data. Exploration Geophysics, 22, 591592.

REEVES CV. 1993. Limitations imposed by geomagnetic variation on high quality aeromagnetic surveys. Exploration Geophysics, 24, 115-116.

URQUHART T. 1889. Decorrugation of Enhanced Magnetic Field Maps. SEG Technical Program Expanded Abstracts 1988, 371-372 pp.

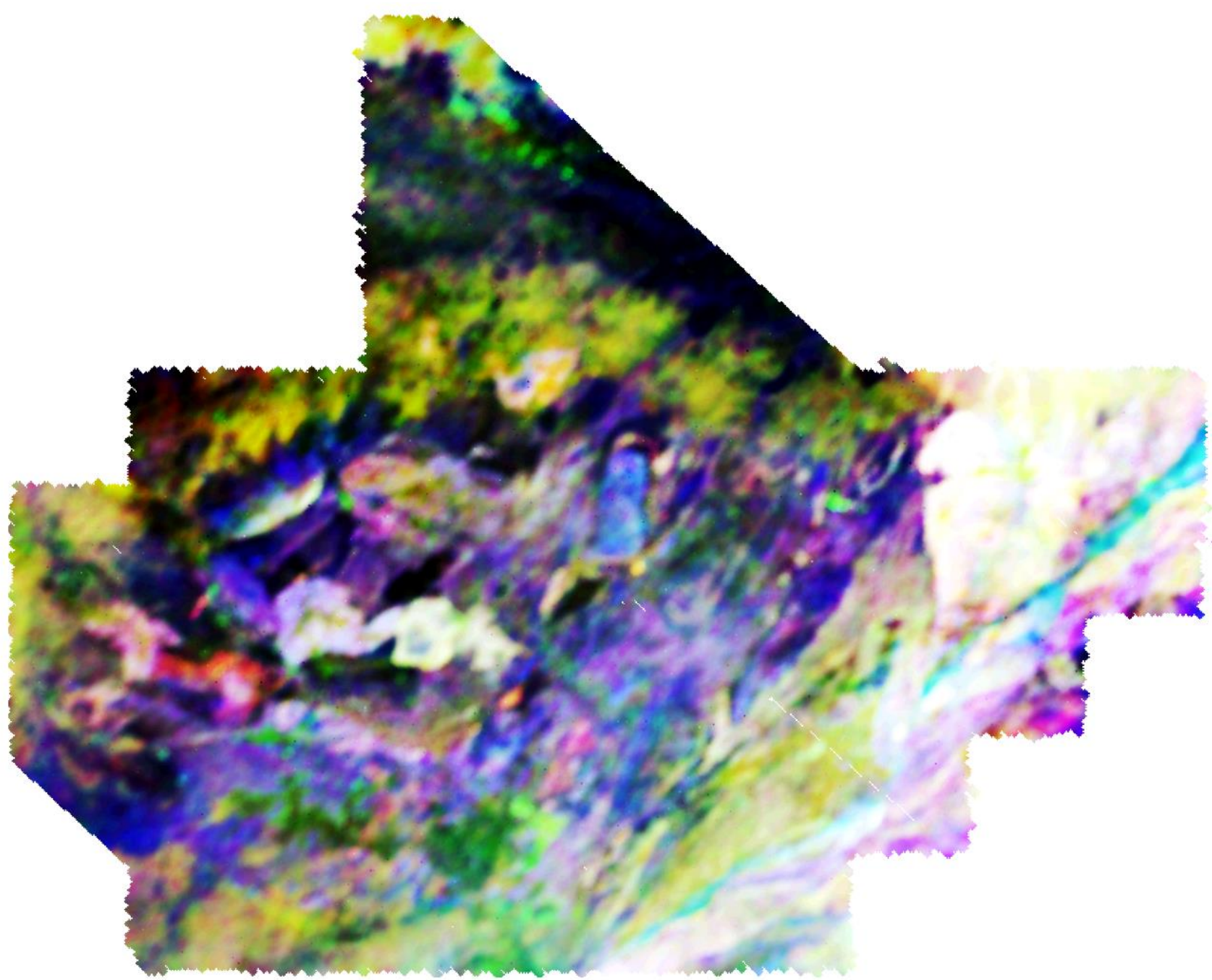

Figure 8 - Ternary (K-Th-U) grid to complete database (E and W parts) of the Camaquã Aerogeophysical Project (Project 1010, RS, 1973). Levelling technique according to Huang (2008). Gridding was performed through simple Kriging (N35E). 
